\title{
Investigating the Efficacy of Focused and Unfocused Corrective Feedback on the Accurate Use of Prepositions in Written Work
}

\author{
Asiah $\mathrm{Kassim}^{1,2}$ \& Lee Luan $\mathrm{Ng}^{1}$ \\ ${ }^{1}$ Faculty of Languages \& Linguistics, Universiti Malaya, Malaysia \\ ${ }^{2}$ Centre for Modern Languages \& Human Sciences, Universiti Malaysia Pahang, Malaysia \\ Correspondence: Asiah Kassim, Centre for Modern Languages \& Human Sciences, Universiti Malaysia Pahang, \\ Lebuhraya Tun Razak, 26300 Gambang, Kuantan, Pahang, Malaysia. Tel: 609-549-3054. E-mail: \\ asiahkassim@gmail.com
}

Received: September 27, 2013 Accepted: November 11, 2013 Online Published: January 6, 2014

doi:10.5539/elt.v7n2p119 URL: http://dx.doi.org/10.5539/elt.v7n2p119

\begin{abstract}
This paper discusses findings from a study investigating feedback efficacy on the accurate use of prepositions by ESL learners in written work over a period of 12 weeks. The study involved two treatment groups and a control group comparing the differential effects of the focused indirect with the unfocused indirect corrective feedback on the uptake and retention measured from the pretest, immediate and delayed posttests. The study also analysed the language-related episodes (LREs) occurring in the collaborative dialogue during the treatment sessions to identify the factors affecting uptake and retention of the corrective feedback in subsequent writing tasks. Findings revealed that both treatment groups outperformed the control group in the posttests, but, there was no significant difference between the unfocused and focused corrective feedback groups. Evidence from the LREs analysis suggests that extensive engagement in all the three functions of the Swain (2005) output hypothesis: noticing, hypothesis testing and metalinguistic, during the collaborative dialogue contribute toward the enhancement of uptake and retention. Since both correction types were equally facilitative in increasing accuracy of preposition usage, teachers may consider using them accordingly in writing tasks.
\end{abstract}

Keywords: written corrective feedback, focused corrective feedback, unfocused corrective feedback, language-related episodes, preposition use

\section{Introduction}

\subsection{Roles of Corrective Feedback in Language Learning}

Corrective feedback (henceforth $\mathrm{CF}$ ) is presumed to be an essential element in language learning and for decades, second language (L2) writing teachers and researchers have been investigating its role and efficacy in second language acquisition. Providing feedback to learners' written work has always been a challenging task as one may not be certain that the feedback given does have effect on the learners' language development. On the teachers' part, it can be discouraging when the energy and time spent on trying to provide feedback to the students, particularly on grammatical errors, do not seem to benefit the learners. This predicament is shared by some of the educators and researchers (e.g., Ferris, 1999; Lee, 2009; Truscott, 1996). Researchers like Truscott (1996) has even put forward the notion that not only corrective feedback is ineffective in helping learners improve their language accuracy, but it can also pose harmful effects on the learning process.

To date, many researchers have tried to negate Truscott's claim by providing empirical evidence on the benefits of corrective feedback on the learners' language development. Nevertheless, studies carried out vary in results as to whether the claims can be contrary to or in agreement with that of Truscott's stance (Bitchener, Young, \& Cameron, 2005; Chandler, 2003; Ellis, Sheen, Murakami, \& Takashima, 2008; Ferris, 2006; Sheen, Wright, \& Moldawa, 2009). Ferris (2006) believes that in order for the feedback to be effective, the types of feedback provided should be given emphasis. F. Hyland and K. Hyland (2006) state that delivering feedback in a variety of "mode" will ensure effectiveness and that these approaches should provide opportunities for learners to interact and revise their work more clearly based on the written corrections given to them. It seems that teachers should be more resourceful in dealing with these feedback issues.

Peterson and McClay (2010) state that most teachers believe corrective feedback is imperative to help students 
know what is wrong and what is right with their work. Thus, generally, teachers will try to provide as much feedback as possible to students, thinking that the more comprehensive the feedback is, the more students will improve in the next writing assignment. Yet, it is not certain to what extent the feedback aids the learners in correcting their linguistic errors in writing tasks. The present study attempts to address these issues by carrying out investigation to determine the effectiveness of corrective feedback and to investigate the differential effects of unfocused and focused CF options in increasing accuracy of prepositions in written work. Strategies employed by the learners and factors influencing uptake and retention of the corrective feedback are also looked into.

One of the reasons why the present study focused on preposition use was due to the fact that a good number of studies have focused on articles in written work and it has been suggested that examining CF efficacy on other linguistic forms could provide insights on the role of corrective feedback in language learning (Bitchener \& Knoch, 2008; 2010; Ellis et al., 2008; among others). Furthermore, Ferris (2006) categorised preposition as 'untreatable' error and idiosyncratic, thus, it is of importance for the present study to find out if CF can be helpful to improve accuracy of prepoisition use, since there are no systematic rules available for learners to refer to in making corrections.

\subsection{Issues on Corrective Feedback Effectiveness}

Much discussion revolving around the issue of whether or not teachers should provide corrective feedback for learners' written work has been raised by a number of researchers (Bitchener et al., 2005; Bitchener \& Knoch, 2008; Ferris, 2006; Truscott, 1996; 1999; 2007). This mostly resulted from Truscott's (1996) notion of abandoning grammar correction because he claims that corrective feedback does not help learners improve linguistic accuracy and it can even be detrimental to the language learning development. On the other hand, being the advocate of the use of corrective feedback in providing assistance to learners' linguistic accuracy, Ferris $(2006 ; 2010)$ has tried to show the effectiveness of corrective feedback in many of her studies along with some other scholars in the field (Bitchener et al., 2005; Bitchener \& Knoch, 2008; 2009; Chandler, 2003; Ellis et al., 2008). However, there are studies investigating the role of corrective feedback in language learning that have yielded findings supporting Truscott's stance, which shows CF as an ineffective means (Sheen et al., 2009; Polio, Fleck, \& Leder, 1998).

While clearly acknowledging the importance of grammar accuracy in written work, Truscott (1996; 1999) strongly believes that learners should not be provided with grammar corrections to avoid hampering their learning progress. One of the arguments for this assertion is that research findings reported in feedback literature may have been misleading in portraying CF effectiveness. Truscott $(1996 ; 2007)$ refers to a number of studies to prove his case (e.g., Chandler, 2003; Robb, Ross, \& Shortreed, 1986). Citing these studies, Truscott (1996; 2007) states that since these studies are not lucidly defining in what constitutes a control group, findings from these studies cannot be considered to address the question of whether grammar correction is indeed effective or not, since there was no comparison made between learners who received CF and those who did not. For instance, the Chandler (2003) study is criticized as not addressing the question of feedback efficacy because Truscott (2007) considers the control group in that study as not methodologically a control group. Citing the Robb et al. (1986) study, Truscott argues that the study does not address the issue of CF effectiveness because all groups showed an increase in accuracy regardless of whether they received feedback or not.

These seemingly unresolved methodological issues that appear to impede any form of agreement on the central problem of feedback efficacy calls for further research. Ellis et al. (2008), Bitchener (2008) and Bitchener and Knoch (2009) have carried out investigations involving a control group that was not provided with any form of feedback. Findings from all these studies indicate that groups that received error corrections, regardless of the feedback types outperformed the groups that received no feedback. Truscott (2007) insisting that error correction is ineffective, attributes the gains in accuracy to other factors that may have influenced the results such as "language experience, maturation" and "writing practice".

Sheen et al. (2009) then conducted a study that comprised an additional group that was required only to complete writing tasks. Findings reveal that the writing practice group improved in the accuracy of the articles use even without any error corrections. In fact, the writing practice group performed better than the group that received unfocused CF. This finding renders support to Truscott's (2007) claims that other factors such as writing practice may benefit the learners in improving accuracy even without being provided with error corrections. Nevertheless, it may be worthwhile to consider that the varied findings from numerous studies are an indication that perhaps the answer may lie in the approaches and types of CF used. 


\subsection{Types of Corrective Feedback}

Unfocused feedback which is claimed to be the common practice in most writing classes, can be classified as the CF that teachers provide for all the language errors committed by the learners (Ellis et al., 2008; Ellis, 2009; Lee, 2009). On the other hand, focused CF is provided intensively for a single error or error category. Ellis (2009) believes that focused CF will provide "rich evidence" for the learners to be aware of the errors committed and that a more focused attention to that particular error may lead to a more enhanced learning. Although many earlier studies employed unfocused corrective feedback to improve language accuracy in writing (e.g., Chandler, 2003; Robb et al., 1986), recent studies (Bitchener, 2008; Bitchener \& Knoch, 2008; 2009; Ellis et al., 2008) suggest a more selective focus in providing feedback and findings from these latter studies have also been encouraging.

In order to determine the relative effectiveness of these two CF options, studies were carried out focusing on the use of English articles. Ellis et al. (2008) attempt to ascertain if there was any difference in feedback efficacy of the focused and unfocused corrections to improve accuracy of English articles used in written tasks. The findings indicate that there is no significant difference between the focused and unfocused groups in improving accuracy in the use of English articles, although there is a pattern suggesting the learners that received focused corrections seem to perform better than the unfocused group. Sheen et al. (2009) also report on a study investigating the differential effects of the two CF options on the accurate use of English articles. Even though all groups demonstrated an increase in accuracy, in both immediate and delayed posttests, focused group significantly outperformed unfocused group in the accuracy scores implying that focused CF is more effective than the unfocused CF when it concerns the use of English articles.

Researcher also looked into the issue of efficacy in terms of direct and indirect feedback. Direct feedback refers to the corrections where learners are provided with the correct forms as opposed to indirect feedback where learners are informed of the errors committed but corrected forms are not provided. Storch and Wigglesworth (2010) suggest that indirect CF may be more effective to facilitate learners' uptake and retention of linguistic forms accuracy in written work than direct CF. According to Ferris and Roberts (2001), direct CF is suitable for learners with low proficiency level and it is unlikely to contribute to long term acquisition. It is also suggested that indirect $\mathrm{CF}$ is a better means to assist learners in improving grammatical accuracy because studies have shown that indirect feedback enables learners to be involved in a deeper processing of the CF (e.g., Ferris, 2006; Lalande, 1982). On the contrary, other studies suggest that direct CF may be more effective in assisting learners improve linguistic accuracy in written work (e.g., Bitchener \& Knoch, 2010; Hashemnezhad \& Mohammadnejad, 2012). Since direct CF provide learners with the correct forms for the errors committed, it may be more helpful for them to make corrections and revise their written work

The diverse findings in the studies discussed here imply that more empirical evidence is needed to inform teachers and researchers in making a resounding evaluation on the effectiveness of different CF options. Thus far, a number of studies that employed selective CF have been focusing on the accurate use of articles in written work (Bitchener \& Knoch, 2008; 2009; Ellis et al., 2008; Sheen et al., 2009; among others). The Bitchener et al. (2005) study that investigated preposition usage in written work compared the effectiveness of direct CF with or without oral conference, produced findings that suggest fluctuating effects of the CF on the learners' accurate use of preposition over a period of time. Other studies that examined the effectiveness of various types of CF discussed an overall learners' performance in the accuracy of various linguistic forms of which preposition was one of the features analysed (e.g., Sach \& Polio, 2007; Storch \& Wigglesworth, 2010). Working on the propositions to further investigate CF efficacy on the 'untreatable' linguistic forms (Bitchener \& Ferri, 2012; Bitchener et al., 2005; Ferris, 2006), the present study aims to determine the effectiveness of indirect focused and focused on the accuracy of prepositions in written work.

\subsection{Contextualising Output Hypothesis}

In determining the impact of $\mathrm{CF}$ on the process of language learning, it is only apt that the output produced by the leaners is taken into consideration. The current study is guided by the framework that is based on Swain's (2005) output hypothesis. Swain (2005) states that learners need to produce the language in order to discover the real potential of learning that takes place. The key concept in this hypothesis is that learners are actively engaged in the process of language learning by producing language output which provides learners with opportunities to use the language. Swain (2005) states that the three functions of the hypothesis are noticing, hypothesis testing and metalinguistics. Acquisition occurs when noticing of certain linguistic forms takes place in a language production. Noticing is important because it provides learners with the information on the "gap" in their interlanguage system. According to Swain (2005), noticing may occur if the gap is made sufficiently salient to 
the learners and in the context of the present study, this is achieved by providing indirect focused or unfocused $\mathrm{CF}$ to the learners' written work.

Learners are further engaged in the learning process by testing their hypothesis on the linguistic forms. This process provides learners with opportunities to produce modified output and test their interlanguage output in the attempt to identify the target-like use of the linguistic form in question. Storch \& Wigglesworth (2010) assert that the more extensive the engagement in the LREs is, the greater the uptake and retention are of the linguistic forms discussed. This is due to the opportunity that learners have to use the language while deliberating on linguistic forms in pair talk tasks.

The third function of the hypothesis is the reflection on the learner's metalinguistic knowledge. The reflection of the learner's linguistic knowledge will lead to the formation of a new knowledge as well as the realization of the gap that exists in the learner's interlanguage system. Swain (2005) states that the engagement of interlocutors having a more or less similar proficiency level in "problem solving" and "knowledge building" enhances the exploration by "stretching" their interlanguage.

In the present study, learners were provided with either focused or unfocused CF to trigger the noticing function. The learners were then provided with the opportunities to reflect on their metalinguistic knowledge. One of the purposes of the study was to find out if there were any differences between the two CF types provided to the learners' written work when they went through this correction stage and the factors that influenced uptake and retention over a period of time.

\subsection{Research Questions}

The study aimed at contributing to the pool of knowledge in the corrective feedback literature by carrying out an investigation grounded on Swain's output hypothesis. This will address the issue of the effectiveness of feedback in increasing linguistic accuracy and the differential effects of two CF options on new pieces of writing. The study also attempted to explore the feedback efficacy from the learners' perspectives. Thus, the study is guided by the following three research foci:

1) Is there any significant difference in the accurate use of prepositions between the learners that receive focused or unfocused corrective feedback and the learners who do not receive corrective feedback?

2) Is there any significant difference between the indirect focused corrective feedback and indirect unfocused corrective feedback in increasing the accuracy of preposition use in written work over a period of time?

3) What are the factors that contribute to the uptake and retention in the accurate use of prepositions resulting from indirect focused and indirect unfocused corrective feedback?

\section{Method}

This section describes the methodology of the present study, which includes the design, context and participants, target linguistic structure, instruments, procedures, scoring and analysis.

The quantitative inquiry of the study involved a pretest, immediate and delayed posttests over a period of 12 weeks to measure the accurate use of prepositions in written work. 90 participants were clustered into three groups and went through two treatments sessions which took place from week three to week five. The first treatment group $(n=30)$ was provided with the focused indirect CF targeted at only preposition use in the written work. The second group $(n=30)$ was provided with the unfocused indirect CF. In addition to the target structure, the participants in the unfocused CF group were also provided with feedback via the use of editing symbols which relate to features such as singular/plural, word choice and mechanics. The participants in the control group $(n=30)$ were required to complete the writing tasks but were not provided with corrective feedback.

The procedures and requirements of the data collection were briefed to the participants during the briefing session. The participants' bio-data were also gathered and the participants were given the opportunity to ask questions before they signed the consent form. Immediate posttest was administered in week five after the second treatment session was completed. Delayed posttest was conducted six-weeks later. Data for the qualitative inquiry on the strategies employed in making corrections and other factors that may have influenced feedback efficacy were gathered from the collaborative dialogue carried out during the treatment sessions.

\subsection{Context and Participants}

The study was conducted at a technical university in the East Coast of Malaysia involving 90 (female, $n=49$; male, $n=41$ ) upper intermediate level second language learners of English. The participants were undergraduates majoring in engineering and they enrolled in the language proficiency courses as part of the 
academic requirements. The average age of the participants in each treatment group was 20 years. Bahasa Melayu was the predominant first language of the participants in the study $(n=56)$, followed by Chinese $(n=$ $22)$ and Tamil $(n=12)$. On average, the participants had gone through 11 years of formal schooling and attended English language lessons from the elementary to high school. At the university level, they attended three semesters of English language proficiency courses and the participants who were in the fourth level were doing a course focusing on reading skills. The undergraduates meet four hours a week in a 14-week semester. For the study, the treatment sessions were carried out outside of class hours. The participants in the two treatment groups attended both sessions and all 90 participants took the three tests administered.

\subsection{Focused Linguistic Forms}

In order to measure CF effectiveness, the study focused on prepositions as the target structure used in the written work of the three condition groups. The selection of the targeted form was made based on the error list identified from 100 scripts of graph descriptions from the previous semester. The participants who took part in the study enrolled in the third English proficiency level the previous semester which focused on academic report writing. One of the components of the course that learners had to produce was graph description. For the purpose of the present study, 100 scripts were randomly selected and analysed for the most frequently committed errors and prepositions were among the highest number of errors $(28 \%)$ committed by the students. In addition, researchers like Ting, Mahathir and Chang (2010) who study on grammatical errors committed by ESL learners in spoken discourse, also reported that prepositions were the most frequently committed errors at $20.6 \%$ from the total of 779 errors identified. Furthermore, prepositions were chosen because in earlier focused CF studies, English articles usage has always been the targeted linguistic structure. Suggestions have been made for further research to determine CF effectiveness on other linguistic forms (Bitchener \& Knoch, 2008; 2009; Ellis et al., 2008; Sheen et al., 2009).

\subsection{Testing and Writing Task Instruments}

The participants were required to describe in about 200 words the graphic prompt of a technological theme. There were five similar graphic prompts used for the three tests and two writing tasks. This writing instrument was chosen from one of the writing task types the students were required to complete in the third level proficiency course. The task required the participants to identify salient information presented in the graph and write the description by including an introductory sentence, discussion of the important information identified and a concluding remark. The task was completed in 30 minutes and the participants were allowed to ask questions about the content of the graph if they needed any clarifications. The 30-minute allocation was proven to be sufficient for the participants to complete the task as conducted in the pilot study.

The main reason for selecting the graph description writing task was because this type of writing involved the use of the target structure as determined from the analysis of the 100 scripts taken from the previous semester. Another rationale for the selection of this task was because the participants in the study were taught on how to write graph descriptions in the previous semester. They were able to produce a 200 -word paragraph without difficulty since these participants had completed level three where they were required to produce a number of graph descriptions as one of the tasks completed for the course.

The five graphic prompts used for the three tests and the two writing tasks have been tested for their reliability and consistency measured using correlation coefficient test. The r-value of the correlation coefficient was calculated to determine the equivalence of forms and the consistency over time ranges from .801 to .834 , signifying strong correlation between the accuracy scores of preposition use in the five written tasks. In other words, the scores of most participants in one written task are similar or equivalent to the scores in another written task, indicating that the instruments used in the present study were reliable and consistent.

\subsection{Treatment Procedures}

The treatment procedure is of two stages, the writing task and the pair talks. For each treatment session, the participants were given 30 minutes to write 200-word graph descriptions on a technological theme. In order to avoid problems in understanding the information from the graph, the participants were allowed to ask questions before they started writing. During the pair talk sessions, together with their corrected writings, the participants were provided with a list of editing symbols for their reference and an A4 paper for them to note down their corrections. The participants in the control group were also required to complete the two writing tasks the same week as the CF treatment groups. However, they were not provided with the corrective feedback. Their written work was given very general comments, such as "Good" and "Well written". 


\subsection{Scoring and Analysis}

The present study defined accuracy as the correct use of prepositions in the appropriate language contexts. The participants' written work was rated adopting the calculation method used in the Sheen et al. (2009) study. Each occurrence of prepositions was counted and each correct use of prepositions is marked as " 1 " and " 0 " for the incorrect uses. To convert the marks into the percentage, the number of correct uses is divided by the number of total uses. The percentages then were keyed in to the SPSS version 16.0 to generate data for the statistical inferential analysis.

In order to address the first and the second research questions, repeated measures ANOVA was calculated to generate statistical information. The accuracy scores of the targeted form in the pretest, immediate and delayed posttests were the dependent variables. The independent variables of these measurements were the treatment conditions (indirect focused, indirect unfocused, control) and the test times (pretest, immediate posttest, delayed posttest). Post-hoc pairwise comparisons using Bonferroni test were calculated to determine the specific means that contributed to the significance in the statistical data.

The second stage of the analysis was derived from the coding of the LREs occurring in the collaborative dialogues recorded during the o treatment sessions. In order to examine the features and strategies of learners' engagement in deliberating error feedback, the present study adapted Storch \& Wigglesworth's (2010) LREs coding procedures. Working on Swain's (2005) output hypothesis, the LREs coding and analysis in the present study took into account the functions of noticing, hypothesis testing and metalinguistic. Noticing function was further categorised into "perfunctory" of which the learners noticed the errors but could not explain why the errors occurred, and "substantive" noticing that took place when the learners noticed the errors and were able to explain why the errors occurred (Qi \& Lapkin, 2001). The hypothesis-testing function was manifested in the collaborative dialogue when learners explored and tried out a number of linguistic forms in making corrections. Swain (2005) states that the "output may sometimes be, from the learner's perspective, a 'trial run' reflecting their hypothesis of how to say (or write) their intent" (p. 476). For the purpose of data coding, this function was categorised into "limited" and "extensive" engagements. Extensive engagement is classified as deliberations that involved suggestions or counter suggestions that may show extended 'trial run' of linguistic forms until they came to an agreement of a correction. On the other hand, limited engagement was when the participants simply read the feedback and provided the correct form without much deliberation.

The coding of the recorded and transcribed pair talks was completed using the WEFT QDA 1.0.1 software. The codings were categorised into three main components; resolution of the errors (correctly, incorrectly, unresolved), noticing (substantive, perfunctory) and hypothesis-testing (limited, extensive). Transcribed recordings from both pair talk sessions were coded using the coding system described above for all deliberations on the CF provided for preposition errors (refer to the coding system used the Storch \& Wigglesworth (2010) study). In order to address the third research question of the study, the classified LREs data were then mapped against the participants' accuracy scores in the three tests to analyse the strategies employed by the participants that may influence uptake and retention of the accurate use of prepositions in written work.

The written tests and the LREs coding were rated by the researcher and an independent rater. $25 \%$ of the scripts from the tests were randomly selected and scored independently using the scores of " 1 " and " 0 ". Cross tabulation descriptive analysis was run to generate kappa value to test for inter-rater reliability and the value of .913 was obtained indicating high reliability. $25 \%$ of the LREs transcribed recordings were also rated by two raters and the average kappa value for the inter-rater reliability of the LREs categories was at 895 .

\section{Results}

The statistical results in this section address the first and the second research questions of the present study. A one-way ANOVA was performed on the pretest scores to verify if there was statistically significant difference among the three condition groups. Results indicate that there was no statistical significant difference among the condition groups: $F(2,87)=.449, p=.640$ indicating that the participants in the three groups were comparatively equal in the use of prepositions in the pretest.

\subsection{Focused and Unfocused CF Efficacy in Increasing the Accurate of Prepositions}

A two-way repeated measures ANOVA was preformed to address the first and the second research questions. Results indicate that the participants who received feedback showed significant increase in the accuracy from the pretest to immediate and delayed posttests: $F(2,58)=11.250, p<.05$ for the focused CF group and $F(2,58)=$ $13.109, p<.05$ for the unfocused CF group. Results also show that the control group's mean scores were not significantly different across the three test times: $F(2,58)=.261, p=.771$, indicating no longitudinal gains in 
the accuracy of preposition use.

Addressing the first research question, the results indicate that learners who received corrective feedback outperformed those who were not provided with corrections. The increase in accuracy was manifested in the accuracy scores of the immediate posttest and retained in the delayed posttest administered six weeks later. The uptake and retention of the accurate use of prepositions by both focused and unfocused CF groups contend the claim that Truscott (1996) made on the ineffectiveness of corrective feedback. The result also verifies the findings of other studies that advocate CF effectiveness in assisting learners' language development (Chandler, 2003; Ellis et al., 2008; Ferris, 2006). With the assumption that CF can indeed assist learners improve accuracy, the issue of whether or not teachers should provide CF for learners' written work is addressed. As Ferris (1999; 2004) points out what should be taken into account is the selection of appropriate CF types in the attempt to ensure that corrections provided are meaningful and facilitative to learning.

The following results address the second research question of the present study.Even though both the Unfocused CF $(p=.000)$ and the Focused CF $(p=.000)$ groups significantly outperformed the control group, there was no significant difference between the two treatment groups in the accuracy scores means on the use of prepositions across the three test times: $F(2,261)=19.506, p=.192$. This implies that participants in both groups receiving either unfocused or focused correction showed similar increase in the accuracy scores means.

Table 1. Group means and standard deviations of prepositions across three test times

\begin{tabular}{lllllll}
\hline & Pretest & \multicolumn{3}{c}{ Immediate Posttest } & \multicolumn{2}{c}{ Delayed Posttest } \\
\cline { 2 - 7 } & $M$ & $S D$ & $M$ & $S D$ & $M$ & $S D$ \\
\hline FCF $(n=30)$ & 71.04 & 9.63 & 77.80 & 9.55 & 78.27 & 9.28 \\
UFCF $(n=30)$ & 72.17 & 9.43 & 81.77 & 7.09 & 81.30 & 6.81 \\
Control $(n=30)$ & 71.13 & 9.99 & 70.37 & 8.19 & 70.20 & 8.21 \\
\hline
\end{tabular}

Table 1 presents the scores means on the accurate use of prepositions across three test times. The standard deviation figures for all the three groups indicate that most participants' accuracy scores ranged within the normal distribution of the scores means.

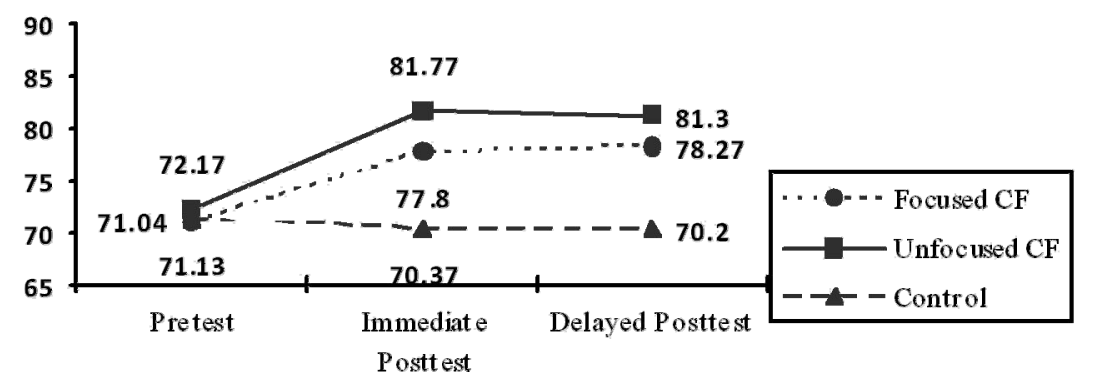

Figure 1. Accuracy scores means across three test times

The line graph in Figure 1 illustrates the scores means pattern of the three condition groups across the three test times. The increase in accuracy is clearly shown for the focused CF and unfocused CF groups in both immediate posttest and delayed posttest. The gap in the plotted lines between the treatment groups and the control group indicates significant difference in the accuracy scores means. However, there was no significant difference between the FCF and UFCF groups in both test times implying that both groups managed to take up and retain accuracy at an almost similar pace.

Unfocused feedback, which is claimed to be the common CF option, has been widely used in language classrooms (Ellis, 2009; Lee, 2009). Thus, it is important for the study to determine whether this common practice is effective compared to the more recent focused CF that seems to have also produced encouraging results (Bitchener \& Knoch, 2008; Ellis et al., 2008). Statistical data indicate that there was no significant 
difference in the accuracy scores of the group that received focused CF and the group that received unfocused $\mathrm{CF}$. Both groups demonstrated uptake of the accurate prepositions uses and they were able to retain the accuracy over a period of time. This implies that teachers may continue to use the unfocused CF in language classrooms, while having the alternative of also using the focused corrective feedback.

\subsection{Factors Influencing Uptake and Retention of the Accurate Use of Prepositions}

Both feedback types have shown facilitative effects on the accuracy scores over a period of time. In order to indentify the factors that influence these results, the third research question explored this issue from the learners' perspectives.

Some of the prevailing factors concluded from the language-related episodes analysis will be discussed in this section. The explanation will be presented by referring to the output hypothesis as the grounding theory of the conducted study. Excerpts from the pair talks are included to provide support for the discussion on the quantitative results addressing research questions one and two. The learners' viewpoint derived from the LREs analysis is essential in identifying the factors that influence feedback efficacy. The following discussion presents interpretations on the functions of noticing, hypothesis testing and metalinguistic/reflective derived from the language-related episodes focusing on the use of prepositions.

The third research question was to find out the factors that may have influenced the uptake and retention of the $\mathrm{CF}$ by the learners in written work over a period of time. While statistical information may be able to provide insights for inference of the CF effectiveness, it is also important to explore the issue from the learners' perspective in order for the teachers to be more thorough in deciding on the CF options. White (2003) states that examining data at individual level is a "welcome trend" since this approach may reveal information on the individual linguistic competence. Bitchener et al. (2005) also mentioned in their reported study about the individual performance factor that may have influenced the notable variation in the accuracy scores across four writing tasks specifically concerning the use of prepositions. For this purpose, the study analysed the LREs to examine the factors that influenced uptake and retention of corrective feedback on prepositions.

The analyses were primarily grounded on the output hypothesis focusing on the three functions that constructed the theory; noticing, hypothesis testing and metalinguistics. Apart from the analysis made within this framework, it has been deduced that the participants' attention towards the feedback provided may be a significant influencing factor that contributed to the uptake and retention of the corrective feedback. Participants must attend to the feedback provided. Chandler (2003) asserts that learners must make corrections for the errors committed to ensure uptake of the CF in subsequent written tasks. The data in the present study indicate that learners who did not attend to the CF failed to show significant increase in accuracy over a period of time. This was especially true when it concerned participants in the focused CF group. Referring to Figure 1, even though there was no statistical significance in the difference of scores means between the focused and unfocused groups, there is a pattern indicating that the scores means of the unfocused group were slightly higher than the focused group in both immediate and delayed posttests.

Participants in the focused group tend to leave out discussing similar feedback since it was easier for them to distinguish the feedback given to certain errors. For example, errors like "at 2008", once they were able to distinguish the errors, they would skip from discussing feedback provided for similar errors. But, for unfocused $\mathrm{CF}$ group, since there were many other corrections on various language forms, they were inclined to discuss all feedback provided regardless of whether the errors were similar or not. This is most probably due to the fact that they were not able to easily distinguish one type of error from another during the pair talk, thus they deliberated over all corrections.

In order to map the pattern of the accuracy score and the two types of noticing (perfunctory and substantive), the scores from the pretest, immediate and delayed posttests of each participant were tabulated in a table together with the coded LREs on substantive and perfunctory noticing. The tests scores and the LREs analysis were tallied and close examination reveals that participants who demonstrated substantive noticing performed better than those who showed only perfunctory noticing. An example of a LRE that shows substantive noticing is given below:

Excerpt 1

1) P7: Here's a "P" error...preposition... “at year 2008".

2) P8: "At"? That's the preposition? That sounds ok, I have that too in my paper, "at year 2008 ".

3) P7: So, why is this wrong? Maybe I just write "year 2008"? 
4) P8: "year 2008"...I think there should be a preposition, maybe "at 2008 ".

5) P7: "at 2008", omit "year"? but "at 2008" does not sound right, it is better with "at year 2008" . Maybe we should change "at" to something else.

7) P8: "at year"... "at" is more suitable for place? Like "at home?", not for time. Maybe for time or year we can use "on"? no..."in"

9) P7: "in year 2008?" Yes...I think "in year" is ok. But maybe we don't need "year"

10) P8: "in 2008"...that sounds ok...like the question here..."web browsers users in 2008 "...yes... I believe this is correct...like the question.

12) P7: Yes...let me write "in 2008".

The pairs deliberated over a preposition error and eventually they were able to explain why it was wrong and identified the correct form to use (lines 4 to 9). Pairs that only demonstrated perfunctory noticing would just simply read the $\mathrm{CF}$ and agreed on a correction. This finding seems to corroborate the results from other studies that suggest the greater role substantive noticing plays in enhancing uptake of corrective feedback that is observed through the analysis of LREs (Qi \& Lapkin, 2001; Sach \& Polio, 2007). However, most of the time, it was quite difficult to determine whether the participants had actually exhibited substantive noticing even when they were able to make the accurate corrections. Mostly, the participants were not able to explain why the error was committed and how it can be corrected. They deliberated and agreed on a form of correction, without providing much explanation on the errors.

Another output hypothesis function is that it provides opportunities for hypothesis-testing. Similar to the Storch \& Wigglesworth (2010) study, learners in the present study who were engaged in the LREs more extensively showed a greater uptake and retention of the CF for the target structure. Referring to Excerpt 1, the participants deliberated extensively over the error and tried out several options before finally agreeing on the correction. Metalinguistic reflection tackles the grammar forms that are in the participants' interlanguage system leading to unlearning to occur (Swain, 2005). In contrast to the findings in the Storch and Wigglesworth (2010) study that implied learners' language conventions that are in contradiction to the feedback provided will hinder the uptake of certain linguistic forms, the present study showed that despite their language conventions, these learners were willing to take up the feedback and change the use of certain linguistic forms. Below is an example of the LREs indicating the uptake of the CF despite the learner's language convention.

Excerpt 2

1) P1: Next, preposition error, "as a conclusion", What's wrong with this one?

2) P2: "as a conclusion", the teacher underlined "as", so you need to change the preposition, you cannot use "as a conclusion", use other preposition.

4) P1: I don't understand why this is wrong, I have always used "as a conclusion", maybe I should write "as conclusion"? no "a".

6) P2: The error is "as", the preposition, not "a", so change "as" to something else.

7) P1: What about your paper? Do you have "as a conclusion"?

8) P2: Let me see, yes, but I used "in conclusion" and the teacher did not underline, mine is correct, "in conclusion".

10) P1: "in conclusion?" that sounds really weird, I always use "as a conclusion", that sounds correct to me... "sebagai kesimpulannya" (literally translated as "as a conclusion"). That's right? "in conclusion" is "dalam kesimpulan" (literally translated as "in conclusion"), weird.

Even though participant 1 (P1) was reluctant to accept the correction (lines 1 to 4), she was willing to change her language conventions and her familiar way of using the preposition (lines 10-12). The "unlearning" of the old and familiar form and the uptake of the new form was subsequently used in the second writing task and retained in the immediate and delayed posttests. The LREs analysis implies that learners' belief on existing language convention may not become a hindrance to the uptake and retention of corrective feedback on the use of prepositions.

\section{Conclusion}

The present study was conducted to address the concern over the role of corrective feedback in assisting learners to improve language accuracy. Studies reporting on the CF role have been inconclusive resulting in the debate of 
whether CF can indeed help learners improve accuracy or hinder the development of language acquisition (Truscott, 1996; 1999). Thus, the first aim of the current investigation was to determine whether learners who received CF would be able to write more accurately in subsequent written tasks over a period of time. In addressing this issue, findings of the present study have proven that $\mathrm{CF}$ is effective to help learners increase accuracy in written work compared to those who were not provided with corrective feedback. The fact that learners were able to retain accuracy in both immediate and delayed posttests seems to denote that CF was also effective in a long run. Having addressed this concern, the study moved to determine the differential effects of two CF options (focused indirect and unfocused indirect). Statistical data indicate that there was no significant difference between the focused and unfocused group with regards to increased accuracy in the use of prepositions. In this case, it can be assumed that teachers may have the options to continue using unfocused CF in writing instructions or to focus the feedback on selected linguistic structures. Further studies are necessary to offer more information on the CF options so that teachers would be able to make beneficial decision in providing written feedback to $\mathrm{L} 2$ learners.

Taking into consideration Goldstein's (2004) concern over the matter of research focus in examining learners' response to $\mathrm{CF}$, the current study attempted to identify the factors that affect $\mathrm{CF}$ efficacy to foster uptake and retention of preposition accurate use. Goldstein (2004) claims that the bulk of the research focuses on the students' correction types in attending to the CF provided and that learners engagement in the revision processes can be considered to be under researched. In line with that, the present study attempts to investigate CF efficacy from the learners' perspectives. The findings from the LREs analysis were observed from the output hypothesis framework. Substantive noticing was one the factors that influenced uptake and retention of the CF. When learners demonstrate understanding on the gaps noticed in their interlanguage system, uptake may lead to retention in the long run.

One of the most significant propositions of the present study in relation to the pedagogical implication is the incorporation of written $\mathrm{CF}$ and collaborative dialogue in the learning process. Learners' noticing, testing of language hypothesis and reflections have been greatly enhanced when learners collaboratively revise their written work based on the indirect FCF and UFCF that they received. These enhanced elements influenced CF efficacy on the uptake and retention of the accurate use of prepositions in written work. Thus, it is suggested that when learners are provided with written $\mathrm{CF}$, collaborative dialogue should be incorporated to ensure engagement with the feedback would occur and revisions are made accordingly. In sum, collaborative dialogue provides the means for noticing, hypothesis testing and metalinguistic reflections which are integral in fostering learning and acquisition.

However, as highlighted by Sach and Polio (2007), it should be noted that there is a tendency of misinterpretation since the analysis of the LREs is "highly inferential". Learners may not verbalise everything that they had in mind during the discussion. In the case of the present study, this is especially true when it concerned deliberation over preposition errors. Learners may not know the reason for the erroneous usage but most of them were able to make corrections accurately. The participants may find it difficult to explain the errors, so they just concentrated on the corrections. Therefore, in interpreting the results, it should be kept in mind that "there is no certain way of knowing whether a given verbalization is a veridical (i.e. complete and accurate) account of a learner's awareness of linguistic input" (Sach \& Polio, 2007, p. 73). Another limitation of the present study is that since the investigation only focused on the use of prepositions, results discussed in this study may not be generalized to other linguistic structures. Therefore, conclusion that may have been made from the findings of the current study should be viewed cautiously and carrying out further studies of similar nature may be able to enhance knowledge in this specific area.

\section{References}

Bitchener, J. (2008). Evidence in support of written corrective feedback. Journal of Second Language Writing, 17, 102-118. http://dx.doi.org/10.1016/j.jslw.2007.11.004

Bitchener, J., \& Ferris, D. R. (2012). Written Corrective Feedback in Second Language Acquisition and Writing. New York: Routledge.

Bitchener, J., \& Knoch, U. (2008). The value of written corrective feedback for migrant and international students. Language Teaching Research, 12(3), 409-431. http://dx.doi.org/ 10.1093/elt/ccn043

Bitchener, J., \& Knoch, U. (2009). The relative effectiveness of different types of direct written corrective feedback. System, 37, 322-329. http://dx.doi.org/10.1016/j.system.2008.12.006

Bitchener, J., Young, S., \& Cameron, D. (2005). The effect of different types of corrective feedback on ESL 
student writing. Journal of Second Language Writing, 14, 191-205. http://dx.doi.org/10.1016/j.jslw.2005.08.001

Chandler, J. (2003). The efficacy of various kinds of error feedback for improvement in the accuracy and fluency of L2 student writing. Journal of Second Language Writing, 12, 267-296. http://dx.doi.org/10.1016/S1060-3743(03)00038-9

Ellis, R. (2009). A typology of written corrective feedback types. ELT Journal, 63(2), 97-107. http://dx.doi.org/10.1093/elt/ccn023

Ellis, R., Sheen, Y., Murakami, M., \& Takashima, H. (2008). The effects of focused and unfocused. System, 36, 353-371. http://dx.doi.org/10.1016/j.system.2008.02.001

Ferris, D. R. (1999). The case for grammar correction in L2 writing classes: A response to Truscott (1996). Journal of Second Language Writing, 8, 1-11. http://dx.doi.org/10.1016/S1060-3743(99)80110-6

Ferris, D. R. (2006). Does error feedback help student writers? New evidence on the short- and long-term effects of written error correction. In K. Hyland, \& F. Hyland (Eds.), Feedback in Second Language Writing: Contexts and Issues (pp. 84-104). Cambridge: Cambridge University Press.

Ferris, D. (2010). Second language writing research and written corrective feedback in SLA. Studies in Second Language Acquisition, 32, 181-201. http://dx.doi.org/ 10.1017/S0272263109990490

Ferris, D. R., \& Roberts, B. (2001). Error feedback in L2 writing classes: How explicit does it need to be? Journal of Second Language Writing, 10, 161-184. http://dx.doi.org/10.1016/S1060-3743(01)00039-X

Goldstein, L. M. (2004). Questions and answers about teacher written commentary and student revision: Teachers and students working together. Journal of Second Language Writing, 13, 63-80. http://dx.doi.org/10.1016/j.jslw.2004.04.006

Hashemnezhad, H., \& Mohammadnejad, S. (2012). A Case for Direct and Indirect Feedback: The Other Side of Coin. English Language Teaching, 5(3), 230-239. http://dx.doi.org/10.5539/elt.v5n3p230

Hyland, K., \& Hyland, F. (2006). Feedback on second language students' writing. Language Teaching, 39, 83-101. http://dx.doi.org/10.1017/S0261444806003399

Lalande, J. F. (1982). Reducing composition errors: An experiment. Modern Language Journal, 66, 140-149. http://dx.doi.org/ 10.1111/j.1540-4781.1982.tb06973.x

Lee, I. (2009). Ten mismatches between teachers' beliefs and written feedback practice. ELT Journal, 63(1), 13-22. http://dx.doi.org/ 10.1093/elt/ccn010

Peterson, S. S., \& McClay, J. (2010). Assessing and providing feedback for student writing in Canadian classrooms. Assessing Writing, 15, 86-99. http://dx.doi.org/10.1016/j.asw.2010.05.003

Polio, C., Fleck, C., \& Leder, N. (1998). 'If only I had more time': ESL learners' changes in linguistic accuracy on essay revisions. Journal of Second Language Writing, 7, 43-68. http://dx.doi.org/10.1016/S1060-3743(98)90005-4

Qi, D. S., \& Lapkin, S. (2001). Exploring the role of noticing in a three-stage second language writing task. Journal of Second Language Writing, 10, 277-303. http://dx.doi.org/10.1016/S1060-3743(01)00046-7

Robb, T., Ross, S., \& Shortreed, I. (1986). Salience of feedback on error and its effect on EFL writing quality. TESOL Quarterly, 20, 83-93. http://dx.doi.org/10.2307/3586390

Sachs, R., \& Polio, C. (2007). Learners' uses of two types of written feedback on a L2 writing revision task. Studies in Second Language Acquisition, 29, 67-100. http://dx.doi.org/10.1017/S0272263107070039

Sheen, Y., Wright, D., \& Moldawa, A. (2009). Differential effects of focused and unfocused written correction on the accurate use of grammatical forms by adult learners. System, 37, 556-569. http://dx.doi.org/10.1016/j.system.2009.09.002

Storch, N., \& Wigglesworth, G. (2010). Learners' processing, uptake, and retention of corrective feedback on

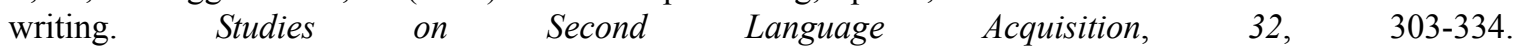
http://dx.doi.org/10.1017/S0272263109990532

Swain, M. (2005). The output hypothesis: Theory and research. In E. Hinkel (Ed.), Handbook of Research in Second Language Teaching and Learning (pp. 471-484). New Jersey: Lawrence Erlbaum Associates.

Ting, S. H., Mahathir, M., \& Chang, S. L. (2010). Grammatical Errors In Spoken English Of University Students 
In Oral Communication Course. GEMA Online ${ }^{R}$ Journal of Language Studies, 10(1), 53-70.

Truscott, J. (1996). The case against grammar correction in L2 writing classes. Language Learning, 46, $327-369$. http://dx.doi.org/ 10.1111/j.1467-1770.1996.tb01238.x

Truscott, J. (1999). The Case for "The Case Against Grammar Correction in L2 Writing Classes": A Response to Ferris. Journal of Second Language Writing, 8(2), 111-122. http://dx.doi.org/10.1016/S1060-3743(99)80124-6

Truscott, J. (2007). The effect of error correction on learners' ability to write accurately. Journal of Second Language Writing, 16, 255-272. http://dx.doi.org/10.1016/j.jslw.2007.06.003

\section{Copyrights}

Copyright for this article is retained by the author(s), with first publication rights granted to the journal.

This is an open-access article distributed under the terms and conditions of the Creative Commons Attribution license (http://creativecommons.org/licenses/by/3.0/). 